\title{
Daily intake of rosehip extract decreases abdominal visceral fat in preobese subjects: a randomized, double-blind, placebo-controlled clinical trial
}

This article was published in the following Dove Press journal:

Diabetes, Metabolic Syndrome and Obesity:Targets and Therapy 6 March 2015

Number of times this article has been viewed

\section{Akifumi Nagatomo' \\ Norihisa Nishida' \\ Ikuo Fukuhara ${ }^{2}$ \\ Akira $\mathrm{Noro}^{3}$ \\ Yoshimichi Kozai ${ }^{3}$ \\ Hisao Sato ${ }^{3}$ \\ Yoichi Matsuura'}

'Research and Development Division, Morishita Jintan Co, Ltd, Osaka, Japan; ${ }^{2}$ Fukuhara Clinic, Hokkaido, Japan; ${ }^{3} \mathrm{New}$ Drug Research Center, Inc., Hokkaido, Japan
Correspondence: Akifumi Nagatomo Research and Development Division, Morishita Jintan Co, Ltd, 2-I I-I,

Tsudayamate, Hirakata,

Osaka 5730I28, Japan

Tel +8I 72800 I044

Fax +8I 728002903

Email a-nagatomo@jintan.co.jp
Background: Obesity has become a great problem all over the world. We repeatedly screened to find an effective food to treat obesity and discovered that rosehip extract shows potent antiobesity effects. Investigations in mice have demonstrated that rosehip extract inhibits body weight gain and decreases visceral fat. Thus, the present study examined the effect of rosehip extract on human body fat in preobese subjects.

Methods: We conducted a 12-week, single-center, double-blind, randomized, placebocontrolled study of 32 subjects who had a body mass index of $\geq 25$ but $<30$. The subjects were assigned to two random groups, and they received one tablet of placebo or rosehip that contained $100 \mathrm{mg}$ of rosehip extract once each day for 12 weeks with no dietary intervention. Abdominal fat area and body fat percent were measured as primary outcomes. The other outcomes were body weight and body mass index.

Results: Abdominal total fat area, abdominal visceral fat area, body weight, and body mass index decreased significantly in the rosehip group at week 12 compared with their baseline levels $(P<0.01)$ after receiving the rosehip tablet intake, and the decreases in these parameters were significantly higher when compared with those in the placebo group. Additionally, body fat percent tended to decrease compared with the placebo group and their baseline level. Moreover, the abdominal subcutaneous fat area was significantly lower in the rosehip group than in the placebo group at week 12 after the initiation of intake $(P<0.05)$. In addition, there were no abnormalities, subjective symptoms, and findings that may indicate clinical problems during the study period.

Conclusion: These results suggest that rosehip extract may be a good candidate food material for preventing obesity.

Keywords: tiliroside, obesity, dietary supplement, randomized clinical trial, Rosa canina L., weight loss

\section{Introduction}

Obesity is one of the most important diseases and has become a global health problem. It is caused when a balance between energy intake and expenditure is lost and is characterized as a state of increased body weight by excessive lipid accumulation in the white adipose tissue. ${ }^{1}$ Hypertrophied fat cells can increase a risk of type 2 diabetes associated with insulin resistance. Obesity can cause dysbolisms such as hyperlipidemia, hypertension, and arteriosclerosis, and these disorders can induce fatal cardiovascular diseases. ${ }^{2}$ Therefore, the prevention and improvement of obesity, particularly decrease of visceral fat is important in the control of these metabolic diseases.

Various functional foods or natural components have been recently developed for preventing or improving obesity as the alternative means of lifestyle improvement or 
medical treatment for obesity. As the result of our screening, we found that tiliroside, a major rosehip seed constituent, has fat metabolism acceleration and glucose clearance improvement effects. ${ }^{3}$

Rosehip, the whole fruit of Rosa canina L. belonging to the family Rosaceae, is popular all over the world. In Europe and America, rosehip is processed widely into jam and juice, used as a vitamin $\mathrm{C}$ supplement, in cosmetics, and as a folklore drug in the form of tisane., ${ }^{4,5}$ The functional capacities of rosehip includes efficacy on diuresis, as a laxative, and as treatments for gout and rheumatism. ${ }^{6,7}$ There have also been reports of several effects including antioxidative ${ }^{8}$ anticold, and anti-inflammatory actions, ${ }^{9}$ inhibitory effects on metabolism of arachidonic acid and formation of cyclooxygenase 1, cyclooxygenase 2 , and leukotriene $\mathrm{B} 4,{ }^{10}$ suppression of inflammation and cancer cell proliferation attributable to anticomplementary effect, ${ }^{11}$ antibacterial action and suppression of experimental nephrolithiasis, ${ }^{12}$ melanin production inhibition, ${ }^{13}$ and antidiarrheal action using a methanol extract of rosehip leaves. ${ }^{14}$ Large-scale clinical studies have confirmed the efficacy of rosehip in treating human knee joint arthropathy. ${ }^{15}$

It is well known that rosehip contains an abundance of vitamin $\mathrm{C}$ and polyphenols. ${ }^{16}$ Especially, tiliroside, a major glycosidic flavonoid isolated from rosehip seed, has a variety of pharmacological activities, eg, an anticomplementary effect, ${ }^{17}$ a hepatic protection action, ${ }^{18}$ an anti-inflammatory and antioxidative action, ${ }^{19}$ an inhibitory effect on the depression of expression of insulin-like growth factor-1 and hypoxia-inducible factor- 1 due to oxidative stress, ${ }^{20}$ and an antibacterial action. ${ }^{21}$

Recently, the antiobesity effects of rosehip have been clarified by in vitro and in vivo studies. Ninomiya et al showed that an $80 \%$ aqueous acetone extract of the whole fruit of $R$. canina L. significantly suppressed body weight gain and prevented increases in the visceral fat in nonobese mice without any changes in diet intake. ${ }^{3}$ They also reported that tiliroside upregulated the expression of peroxisome proliferator-activated receptor $\alpha$ messenger RNA in the liver. We showed that an aqueous ethanol extract of rosehip inhibited lipid accumulation in adipocytes using 3T3-L1 cells and diet-induced obese mice. ${ }^{22}$ Andersson et al reported that rosehip juice decreased the systolic blood pressure and plasma cholesterol levels in obese subjects. ${ }^{23}$ However, no clinical trials have evaluated the antiobesity effects of rosehip.

Obesity is defined by the World Health Organization classification as a body mass index $(\mathrm{BMI}) \geq 30 \mathrm{~kg} / \mathrm{m}^{2}$, where a person with a BMI $\geq 25 \mathrm{~kg} / \mathrm{m}^{2}$ but $<30 \mathrm{~kg} / \mathrm{m}^{2}$ is classified as preobese. ${ }^{24}$ In addition, based on the diagnostic criteria for obesity provided by the Japan Society for the Study of Obesity in 2011, an abdominal visceral fat area $\geq 100 \mathrm{~cm}^{2}$ is an important factor in obesity-related metabolic disorders. ${ }^{25}$ In the present study, we targeted preobese subjects and confirmed the antiobesity effects of rosehip extract, where a reduction in the abdominal body fat area and body fat percent were the primary outcome.

\section{Materials and methods}

\section{Study design}

A single-center, double-blind, randomized, placebo-controlled study was designed to evaluate the efficacy of rosehip extract. All experiments conformed to the Helsinki Declaration (adopted in 1964 and amended in 2008) and were conducted under the control of the principal investigator. The study protocol and all related documents were approved by Miyawaki Orthopedics Clinic Institutional Review Board. Appropriate explanations were provided to the subjects for important factors including the study purpose, contents, methods, and predicted adverse reactions. Informed consent was voluntarily obtained from each subject in writing. The study was performed in Fukuhara Clinic in Eniwa, Hokkaido, Japan, from August 2011 to December 2011.

\section{Subjects}

In total, 152 subjects agreed to participate in the study, who were paid volunteers enrolled by the New Drug Research Center Inc. (Previously known as: New Drug Development Research Center Inc.), and 32 subjects (16 males and 16 females) who met the following inclusion and exclusion criteria were selected by screening (Figure 1, Table 1). The 32 subjects were assigned to two equal groups to avoid bias related to sex, BMI, and body fat percentage.

\section{Materials}

Rosehip extract (Rosehip Polyphenol EX ${ }^{\mathrm{TM}}$, Morishita Jintan Co, Ltd, Osaka, Japan) comprised an aqueous ethanol extract of rosehip containing its seeds, dextrin, and cyclodextrin. This extract contains not less than $0.1 \%$ of tiliroside. The rosehip tablet contained $100 \mathrm{mg}$ of rosehip extract and excipients, and the placebo tablet was indistinguishable from the rosehip tablet. The compositions and nutritional contents of both the tablets are shown in Table 2.

\section{Study schedule and measurements}

All subjects received one rosehip or placebo tablet once a day for 12 weeks by chewing, and they visited the clinic for 


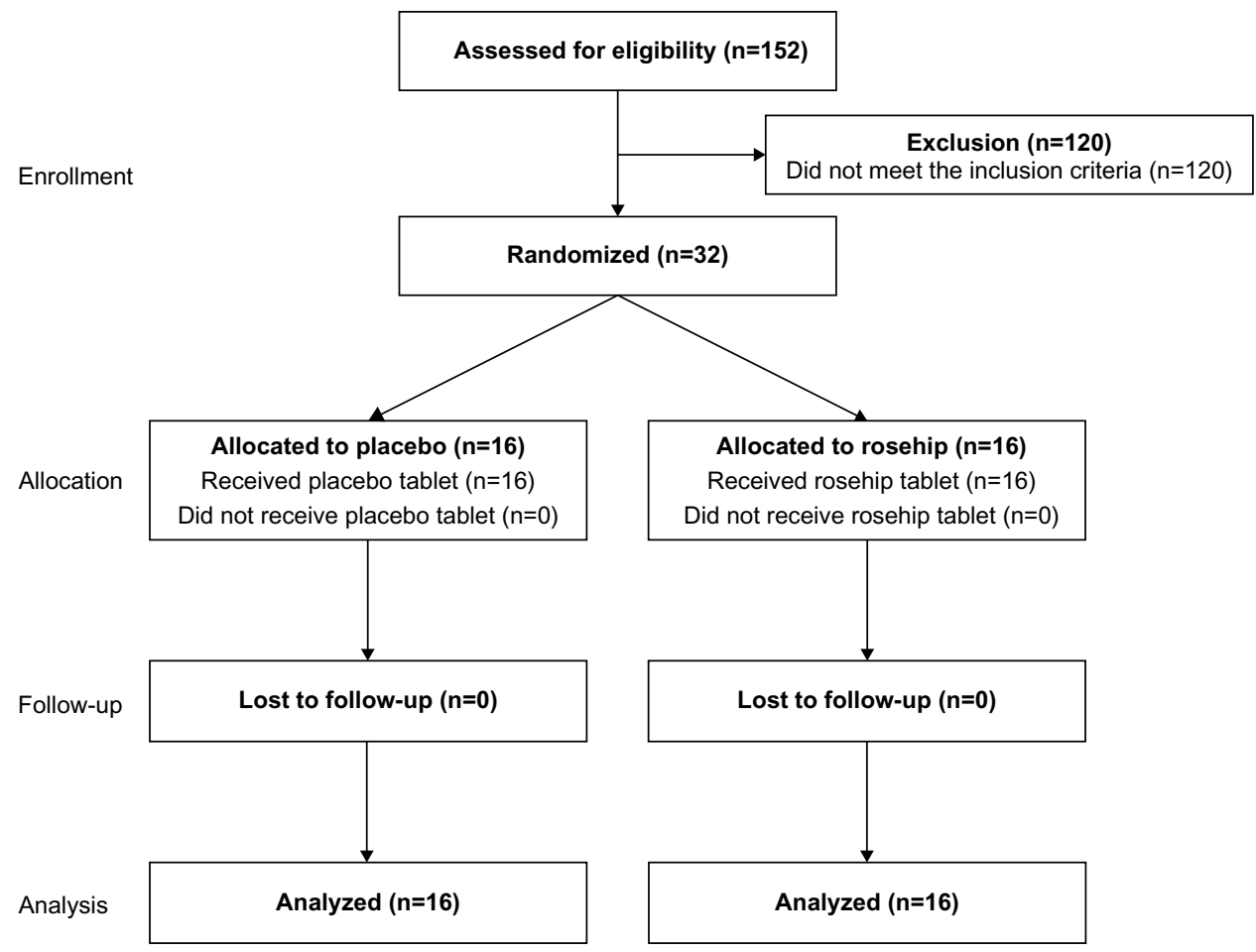

Figure I Flow diagram through the phases of the study.

assessments and measurements at the start of intake (W0) and on the 4th (W4), 8th (W8), and 12th week (W12). The subjects were allowed to drink only water after $9 \mathrm{pm}$ on the day before the visit for examinations. During the study period, the subjects were not permitted to use medical products or

Table I Inclusion and exclusion criteria for the selection of study participants

\section{Inclusion criteria}

BMI: $\geq 25.0 \mathrm{~kg} / \mathrm{m}^{2}$, and $<30.0 \mathrm{~kg} / \mathrm{m}^{2}$

Sufficient understanding of the study purpose and methods, and predicted adverse reactions

Voluntarily agreed to participate in the study in writing

\section{Exclusion criteria}

History of drug allergy

Excessive smoking habit, alcohol addiction, and markedly irregular eating habits

Significant impediment of liver function or renal function Surgical history of the gastrointestinal tract region including gastric resection, gastro-enterorrhaphy, and intestinal resection Donated $400 \mathrm{~mL}$ blood within 12 weeks before the intake of the test food, $200 \mathrm{~mL}$ blood within 4 weeks before the intake of the test food, or donated blood components (donation of plasma components and thrombocyte components) within 2 weeks before the intake of the test food

Works until late in the evening and irregular shift workers Pregnant women or women who are nursing or planning for pregnancy within 6 months Judged as ineligible to participate in the study by an investigator Abbreviation: BMI, body mass index. foods with lipid-lowering or body fat-reducing actions, and we instructed the subjects not to change their life patterns greatly compared with that before the initiation of the study. All subjects were assessed to determine their physical parameters (body weight, body fat percentage, BMI, body temperature, blood pressure, and heart rate), hematological parameters (white blood cells, red blood cells, hemoglobin, hematocrit, and platelets), blood biochemical parameters (total protein [TP], albumin, albumin/globulin ratio, aspartate

Table 2 Composition and nutritional content of test foods

\begin{tabular}{lll}
\hline & \multicolumn{2}{l}{$\begin{array}{l}\text { Serving size: I tablet } \\
\text { (I,500 } \mathbf{~ m g})\end{array}$} \\
\cline { 2 - 3 } & Placebo & Rosehip \\
\hline Composition & & \\
Rosehip extract (mg) & 0.0 & 100.0 \\
Maltitol (mg) & 933.0 & 833.0 \\
Dextrin (mg) & 150.0 & 150.0 \\
Crystalline cellulose (mg) & 135.0 & 135.0 \\
Citric acid (mg) & 100.0 & 100.0 \\
Lemon juice (mg) & 50.0 & 50.0 \\
Lemon flavoring (mg) & 30.0 & 30.0 \\
Others (mg) & 102.0 & 102.0 \\
Nutritional content & & \\
Energy (kcal) & 4.35 & 4.55 \\
Protein (g) & 0.002 & 0.002 \\
Carbohydrate (g) & 1.361 & 1.353 \\
Fat (g) & 0.077 & 0.081 \\
\hline
\end{tabular}


aminotransferase, alanine aminotransferase, $\gamma$-glutamyl transpeptidase, fasting blood sugar, total cholesterol, highdensity lipoprotein cholesterol, low-density lipoprotein cholesterol, triglyceride, uric acid, urea nitrogen, creatinine, $\mathrm{Na}, \mathrm{K}, \mathrm{Cl}$, and $\mathrm{Ca}$ ), urinalysis (urine protein, urine glucose, urobilinogen, bilirubin, ketone body, occult blood, specific gravity, and $\mathrm{pH}$ ), and abdominal visceral and subcutaneous fat areas. All biochemical analyses were performed in Daiichi Kishimoto Clinical Laboratory Co, Ltd (Hokkaido, Japan) using the automatic analyzers XE-2100 (Sysmex Corp, Hyogo, Japan) for hematological analysis, JCA-BM8060 (JEOL Ltd, Tokyo, Japan) for blood biochemical analysis, and AX-4280 (Arkray, Inc., Kyoto, Japan) for urinalysis.

\section{Dietary record and physical activity}

To determine the energy intake and consumption, we collected meal survey slips where the subjects described their food content and the number of steps counted by a pedometer for 3 days prior to each visit at W0, W8, and W12, and we analyzed the data according to the procedure described by Maki et al. ${ }^{26}$ Based on the meal records, a nutritionist calculated the energy intake and the amount of carbohydrates, fat, and proteins consumed. The energy consumption was calculated as the sum of the basal metabolic rate and kinetic energy. The basal metabolism is usually calculated as the "basal metabolism standard value $\times$ body weight", but in this study, because the basal metabolism becomes excessive in obese subjects, it was calculated using the ideal body weight based on the height. Further, based on the assumption that the kinetic energy was 3.3 metabolic equivalents for males and 3.0 metabolic equivalents for females, the energy consumption (kcal) was calculated by multiplying the walking time from the number of steps by the kinetic energy (metabolic equivalents), body weight, and $1.05(\mathrm{kcal} / \mathrm{kg} / \mathrm{h}) .{ }^{27}$

\section{Physical assessment}

Body weight was measured using the normal method, and BMI was calculated as body weight/height ${ }^{2}$. Body fat percentages were determined using body composition analyzer (TBF-310, Tanita Corp, Tokyo, Japan). Computed tomography (CT) scans were performed using a CT-W450 CT scanner system (Hitachi Medical, Tokyo, Japan). Abdominal body fat areas (subcutaneous and visceral fat areas) were calculated based on an abdominal CT scan image using visceral fat measurement software (Fat Scan ${ }^{\mathrm{TM}}$ Ver. 3.0, N2 Systems Inc., Osaka, Japan). The total fat area was calculated as the sum of the subcutaneous and visceral fat areas. To consider the risk of radiation exposure in subjects, CT scans were performed only on W0, W8, and W12.

\section{Safety assessment}

The subjects entered their subjective symptoms in a subject diary. At W0, W4, W8, and W12, the investigator conducted a medical interview with the subjects based on the subject diary and the health status of the subjects was examined by auscultation and percussion. Body temperature, blood pressure, and pulse were measured at W0, W4, W8, and W12, and hematology tests, blood biochemical examinations, and urinalysis were performed at W0, W8, and W12.

\section{Statistical analysis}

Mean values and standard deviations of each datum were calculated for each group. A paired $t$-test was used to compare the data before and after the intake within a group. The confirmation of homoscedasticity between the placebo and the rosehip groups was conducted using the $F$-test. If the homoscedasticity was verified, a Student's $t$-test was used, whereas Welch's $t$-test was used for comparisons if the variances were unequal. In addition, a signed rank sum test was used for intergroup comparisons of the semiquantitative urine values before and after the intake, and Wilcoxon's rank sum test was used for comparisons between the placebo and test food groups. A $P$ value less than 5\% was considered to be significant. Statistical analysis was performed using Microsoft Excel $^{\circledR} 2003$ (Microsoft Corp, Redmond, WA, USA) and $\mathrm{SAS}^{\circledR}$ 9.1.3 Foundation (SAS Institute, Cary, NC, USA).

\section{Results}

The test food intake rates for the placebo group and the rosehip group at 12 weeks were $99.5 \%$ and $99.6 \%$, respectively. No subject left during the study period, and no outliers were observed for any parameter. Thus, all data were subjected to statistical analysis.

Table 3 shows the background data for the subjects. The abdominal total fat and abdominal visceral fat areas were somewhat higher in the control food group compared with the test food group; however, no significant difference was observed between the two groups ( $P=0.32$ for the abdominal total fat area and $P=0.21$ in the abdominal visceral fat area). In addition, there were no significant differences between the two groups in terms of the other parameters. Table 4 represents the energy intake and consumption, which was calculated based on the number of steps counted and the basal metabolism. No significant intragroup and intergroup 
Table 3 Characteristics of the subjects at baseline

\begin{tabular}{lcc}
\hline & $\begin{array}{l}\text { Placebo group } \\
(\mathbf{n}=\mathbf{l 6})\end{array}$ & $\begin{array}{c}\text { Rosehip group } \\
(\mathbf{n}=\mathbf{1 6})\end{array}$ \\
\hline Age $($ year $)$ & $50.6 \pm 13.7$ & $50.1 \pm 9.2$ \\
Height $(\mathrm{cm})$ & $161.51 \pm 7.84$ & $161.81 \pm 7.62$ \\
Body weight $(\mathrm{kg})$ & $70.01 \pm 8.36$ & $70.31 \pm 6.19$ \\
Body fat percent $(\%)$ & $31.34 \pm 4.93$ & $30.56 \pm 6.96$ \\
BMl $\left(\mathrm{kg} / \mathrm{m}^{2}\right)$ & $26.78 \pm 1.53$ & $26.84 \pm 1.37$ \\
Abdominal fat area $\left(\mathbf{c m}^{2}\right)$ & & \\
Total & $305.35 \pm 59.45$ & $286.61 \pm 44.46$ \\
Subcutaneous & $200.39 \pm 61.95$ & $197.94 \pm 56.45$ \\
Visceral & $104.96 \pm 34.24$ & $88.67 \pm 36.96$ \\
SBP $(\mathrm{mm}-\mathrm{Hg})$ & $132.28 \pm 17.75$ & $137.03 \pm 20.08$ \\
DBP $(\mathrm{mm}-\mathrm{Hg})$ & $80.84 \pm 9.89$ & $83.91 \pm 14.29$ \\
FBS $(\mathrm{mg} / \mathrm{dL})$ & $88.7 \pm 10.7$ & $83.9 \pm 7.7$ \\
Cho $(\mathbf{m g} / \mathrm{dL})$ & & \\
Total-Cho & $205.1 \pm 25.7$ & $210.1 \pm 25.7$ \\
HDL-Cho & $60.3 \pm 11.6$ & $55.8 \pm 9.2$ \\
LDL-Cho & $126.8 \pm 23.6$ & $137.4 \pm 21.8$ \\
\hline
\end{tabular}

Notes: Values represent the mean \pm SD. There were no significant differences between the groups.

Abbreviations: BMI, body mass index; Cho, cholesterol; DBP, diastolic blood pressure; FBS, fasting blood sugar; HDL, high-density lipoprotein; LDL, low-density lipoprotein; SBP, systolic blood pressure; SD, standard deviation.

differences were observed; thus, there were unlikely to have been any major changes in the lifestyles of the subjects during the study period.

The results of the physical assessment of the placebo group and the rosehip group are shown in Table 5. The measurement values at $\mathrm{W} 12$ were compared with those at W0, which showed significant decreases in the body weight and $\mathrm{BMI}$ in the rosehip group; the decreases in the body weight and BMI were significantly larger at W12 in the rosehip group than in the placebo group. Moreover, at W12, the body fat percentage was lower in the rosehip group compared with that in W0, but the difference was not significant. At W8 and $\mathrm{W} 12$, the abdominal visceral fat area in the rosehip group significantly decreased compared with the area at W0, and the decrease in the area at W12 was significantly larger than that in the placebo group. However, at W12, the abdominal total fat area in the rosehip group was significantly lower than that at W0, where the decrease was significantly larger than that in the placebo group. In contrast, there was no significant intragroup variation in the abdominal subcutaneous fat area, but the decrease in this area in the rosehip group at W12 was significantly larger than that in the placebo group. Further, blood pressure was measured using an automated sphygmomanometer, and pulse rates were measured at the same time as the blood pressure. The results of the measurement are also shown in Table 5.

The blood biochemical parameters, hepatic functional markers, fasting blood sugar, and serum lipids, which are cardiovascular disease risk factors, and other parameters, were measured (Table 6). In the rosehip group, TP (W8), fasting blood sugar (W8), high-density lipoprotein cholesterol (W12), and systolic blood pressure (W4) changed significantly from $\mathrm{W} 0$, but the variations were within the normal physiological range.

In the rosehip group, the following adverse events were recorded: common cold in four cases, headache in four cases, pyrexia and cough in two cases each, and sore throat, congested nose, loss of appetite, and abdominal pain in one case each. Furthermore, the adverse events observed in the placebo group were common cold in five cases, headache in three cases, pyrexia/cough in one case, and abdominal pain in one case. All these events were transient, and there was no observed aggravation due to the continuous intake of the placebo and the rosehip tablet in each group. There were no clinically problematic abnormalities or findings according to the physical assessments, blood biochemical and hematological parameters (Table 7), urinalysis (Table 8), and the medical interview by the investigator, which included auscultation and percussion.

\section{Discussion}

The World Health Organization published diagnostic criteria for a syndrome called "metabolic syndrome" in 1998, and there have been extensive subsequent discussions/reviews on these diagnostic criteria. ${ }^{28}$ Metabolic syndrome is a state that combines the risk factors of high blood sugar, high blood

Table 4 Changes in energy intake and energy consumption after the daily intake of placebo or rosehip

\begin{tabular}{|c|c|c|c|c|}
\hline & Group & Wo & W8 & WI2 \\
\hline \multirow[t]{2}{*}{ Energy intake (kcal) } & Placebo & $2,098.78 \pm 480.92$ & $1,920.00 \pm 499.58$ & $\mathrm{I}, 953.3 \mathrm{I} \pm 409.77$ \\
\hline & Rosehip & $\mathrm{I}, 954.73 \pm 386.26$ & $|, 88| . \mid I \pm 458.54$ & $\mathrm{I}, 856.84 \pm 354.58$ \\
\hline \multirow[t]{2}{*}{ Energy consumption (kcal) } & Placebo & $|, 480.57 \pm| 88.14$ & $1,516.07 \pm 199.13$ & I,497.07 \pm 209.55 \\
\hline & Rosehip & $1,501.12 \pm 152.12$ & $\mathrm{I}, 490.68 \pm 175.76$ & $\mathrm{I}, 498.37 \pm 155.34$ \\
\hline
\end{tabular}

Notes: Values represent the mean \pm SD. There were no significant differences between the groups. Energy intake was calculated based on the meal survey slips. Energy consumption was calculated by multiplying kinetic energy (the walking time calculated from the number of steps), body weight, and coefficient ( 1.05 ).

Abbreviations: SD, standard deviation; W0, start of the intake; W8, 8th week; WI2, 12th week. 
Table 5 Changes in physical assessment parameters after the daily intake of placebo or rosehip

\begin{tabular}{|c|c|c|c|c|c|}
\hline & Group & Wo & W4 & W8 & WI2 \\
\hline \multirow[t]{2}{*}{ Body weight (kg) } & Placebo & $70.01 \pm 8.36$ & $70.75 \pm 8.0 \mathrm{I}^{\#}\left(0.74 \pm \mathrm{I} .05^{\#}\right)$ & $70.50 \pm 7.82(0.49 \pm I . I I)$ & $69.75 \pm 8.30(-0.26 \pm 1.34)$ \\
\hline & Rosehip & $70.31 \pm 6.19$ & $70.33 \pm 6.25\left(0.01 \pm 0.83^{*}\right)$ & $69.7 I \pm 6.43\left(-0.60 \pm I .2 I^{*}\right)$ & $68.91 \pm 6.5 I^{\# \#}\left(-1.40 \pm 1.52^{* \#}\right)$ \\
\hline Body fat & Placebo & $31.34 \pm 4.93$ & $31.15 \pm 5.15(-0.19 \pm 1.65)$ & $30.92 \pm 5.28(-0.42 \pm 2.00)$ & $31.08 \pm 5.40(-0.26 \pm 1.54)$ \\
\hline percentage (\%) & Rosehip & $30.56 \pm 6.96$ & $30.48 \pm 6.86(-0.08 \pm 1.68)$ & $30.29 \pm 7.17(-0.28 \pm 2.44)$ & $29.56 \pm 6.16(-1.00 \pm 1.88)$ \\
\hline \multirow[t]{2}{*}{ BMI $\left(\mathrm{kg} / \mathrm{m}^{2}\right)$} & Placebo & $26.78 \pm 1.53$ & $27.06 \pm I .38^{\#}\left(0.28 \pm 0.4 I^{\#}\right)$ & $26.97 \pm 1.36(0.19 \pm 0.42)$ & $26.68 \pm 1.55(-0.10 \pm 0.5 \mathrm{I})$ \\
\hline & Rosehip & $26.84 \pm 1.37$ & $26.84 \pm 1.39\left(0.01 \pm 0.32^{*}\right)$ & $26.62 \pm 1.45\left(-0.22 \pm 0.47^{*}\right)$ & $26.30 \pm 1.52^{\#}\left(-0.54 \pm 0.59^{* \#}\right)$ \\
\hline \multirow{2}{*}{$\begin{array}{l}\text { Abdominal total } \\
\text { fat area }\left(\mathrm{cm}^{2}\right)\end{array}$} & Placebo & $305.35 \pm 59.45$ & Not measured & $304.15 \pm 60.79(-1.20 \pm|| .84)$ & $307.44 \pm 60.73(2.09 \pm|5.5|)$ \\
\hline & Rosehip & $286.6 \mathrm{I} \pm 44.46$ & Not measured & $279.73 \pm 51.68(-6.88 \pm 17.85)$ & $268.13 \pm 55.78^{\ldots}\left(-18.48 \pm 23.02^{* *}\right)$ \\
\hline \multirow{2}{*}{$\begin{array}{l}\text { Abdominal } \\
\text { subcutaneous fat } \\
\text { area }\left(\mathrm{cm}^{2}\right)\end{array}$} & Placebo & $200.39 \pm 61.95$ & Not measured & $199.52 \pm 61.30(-0.87 \pm 8.99)$ & $203.64 \pm 62.25(3.24 \pm 13.42)$ \\
\hline & Rosehip & $197.94 \pm 56.45$ & Not measured & $197.05 \pm 57.65(-0.89 \pm 15.76)$ & $188.72 \pm 53.72(-9.23 \pm \mid 7.70 *)$ \\
\hline \multirow{2}{*}{$\begin{array}{l}\text { Abdominal visceral } \\
\text { fat area }\left(\mathrm{cm}^{2}\right)\end{array}$} & Placebo & $104.96 \pm 34.24$ & Not measured & $104.63 \pm 37.64(-0.33 \pm 10.05)$ & $103.81 \pm 32.21(-1.15 \pm 10.15)$ \\
\hline & Rosehip & $88.67 \pm 36.96$ & Not measured & $82.68 \pm 37.05^{\# \prime}\left(-5.99 \pm 5.55^{\# \#}\right)$ & $79.41 \pm 34.92^{* \ldots \#}\left(-9.26 \pm 10.72^{*}\right)$ \\
\hline \multirow[t]{2}{*}{$\mathrm{SBP}(\mathrm{mm} \mathrm{Hg})$} & Placebo & $|32.28 \pm| 7.75$ & $129.63 \pm 16.48$ & $131.66 \pm 18.04$ & $|29.53 \pm| 7.3 \mid$ \\
\hline & Rosehip & $137.03 \pm 20.08$ & $129.25 \pm 17.05^{\#}$ & $132.44 \pm \mid 5.54$ & $133.28 \pm 13.03$ \\
\hline \multirow[t]{2}{*}{$\mathrm{DBP}(\mathrm{mm} \mathrm{Hg})$} & Placebo & $80.84 \pm 9.89$ & $78.69 \pm 11.14$ & $79.69 \pm 11.09$ & $78.88 \pm 12.39$ \\
\hline & Rosehip & $83.91 \pm 14.29$ & $80.72 \pm 12.29$ & $81.09 \pm 12.89$ & $82.53 \pm 11.18$ \\
\hline \multirow[t]{2}{*}{ HR (bpm) } & Placebo & $66.25 \pm 8.64$ & $67.69 \pm 9.86$ & $68.03 \pm 10.64$ & $67.75 \pm 10.43$ \\
\hline & Rosehip & $65.03 \pm 9.23$ & $67.50 \pm 11.54$ & $66.34 \pm 9.43$ & $65.38 \pm 7.66$ \\
\hline
\end{tabular}

Notes: Values represent the mean \pm SD. Figures in parentheses represent the changes from W0 for each group. There were significant differences between the groups according to the Student's $t$-test or Welch's $t$-test $(* P<0.05 ; * * P<0.01)$. In addition, there were significant differences from the W0 for each group according to the paired t-test $\left({ }^{\#} P<0.05 ;{ }^{\#} P<0.01\right)$.

Abbreviations: BMI, body mass index; DBP, diastolic blood pressure; HR, heart rate; SBP, systolic blood pressure; SD, standard deviation; W0, start of the intake; W4, 4th week; W8, 8th week; WI2, I2th week.

pressure, and hyperlipidemia due to visceral fat type obesity (visceral fat obesity/abdominal obesity). Study groups in various countries have reported that the cardiovascular disease risk is increased in subjects with metabolic syndrome. ${ }^{29-31}$

Frequent attempts have been made to lower the risk of cardiovascular diseases by decreasing visceral fat in studies of obese subjects. The "VACATION-J study" of Japanese subjects showed that an increase in visceral fat heightened the risk of cardiovascular diseases. ${ }^{32}$ In addition, a direct correlation was reported between decreased visceral fat and improvement in cardiovascular disease risk factors, including high blood pressure, hypo-high-density lipoprotein cholesterolemia, hyper-low-density lipoprotein cholesterolemia, hypertriglyceridemia, and fasting hyperglycemia. ${ }^{33}$ Czernichow et al reported that abdominal obesity rather than BMI is related to death risk due to cardiovascular diseases. ${ }^{34}$ Matsushita et al conducted a study of 6,292 Japanese subjects (5,606 males with a mean BMI of $24.1 \mathrm{~kg} / \mathrm{m}^{2}$ and 686 females with a mean BMI of $23.0 \mathrm{~kg} / \mathrm{m}^{2}$ ), which confirms that the abdominal visceral fat area is a better index of metabolic syndrome than the abdominal subcutaneous fat area and waist circumference..$^{35}$

In an analysis of the effects of rosehip on cardiovascular disease risk factors, Andersson et al showed that a rosehip supplement suppressed the progression of diabetes in $\mathrm{C} 57 \mathrm{BL} / 6 \mathrm{~J}$ mice and that downregulation of the lipogenic program in the liver was one of the mechanisms related to this effect. ${ }^{36}$ They also examined the effects of rosehip juice on cardiovascular disease risk markers for type 2 diabetes and circulatory diseases using a randomized, double-blind, crossover method with obese human subjects. ${ }^{23}$

Based on the reports described earlier, we planned and conducted a clinical study to determine the antiobesity effects of rosehip extract. Obtained results suggest that rosehip extract could lead to weight loss, reducing the risk of cardiovascular disease.

The rosehip extract used in this study is commercially available as a functional food ingredient named "Rosehip Polyphenol EX", which includes $\geq 0.1 \%$ tiliroside as an active component. Prior to starting the study, we confirmed that tiliroside content in the rosehip extract was $0.12 \%$. We showed that an aqueous ethanol extract of rosehip inhibits lipid accumulation in the adipocytes..$^{22}$ In addition, Ninomiya et al administered $0.1-10 \mathrm{mg} / \mathrm{kg}$ of tiliroside to mice for 2 weeks and observed the suppression of body weight gain, decreased amount of visceral fat, and they also found that peroxisome proliferator-activated receptor messenger RNA was upregulated in the liver of tiliroside-administered mice. ${ }^{3}$ Furthermore, Goto et al demonstrated that tiliroside stimulates fatty acid oxidation in obesity model KK-Ay mice. ${ }^{37}$ These reports indicate that the antiobesity effects of rosehip extract 
Table 6 Changes in blood biochemical parameters after the daily intake of placebo or rosehip

\begin{tabular}{|c|c|c|c|c|c|}
\hline & Standard range & Group & Wo & W8 & WI2 \\
\hline \multirow[t]{2}{*}{$\mathrm{TP}(\mathrm{g} / \mathrm{dL})$} & $6.5-8.2$ & Placebo & $7.19 \pm 0.25$ & $7.29 \pm 0.33$ & $7.23 \pm 0.24$ \\
\hline & & Rosehip & $7 . \mid 8 \pm 0.31$ & $7.31 \pm 0.36^{\#}$ & $7.19 \pm 0.33$ \\
\hline \multirow[t]{2}{*}{ Albumin (g/dL) } & $3.7-5.5$ & Placebo & $4.26 \pm 0.24$ & $4.24 \pm 0.28$ & $4.19 \pm 0.31$ \\
\hline & & Rosehip & $4.34 \pm 0.17$ & $4.26 \pm 0.17$ & $4.26 \pm 0.19$ \\
\hline \multirow[t]{2}{*}{$\mathrm{A} / \mathrm{G}$ ratio } & $1.30-2.00$ & Placebo & $1.464 \pm 0.161$ & $1.407 \pm 0.198^{\#}$ & $1.389 \pm 0.189^{\#}$ \\
\hline & & Rosehip & $1.55 \mathrm{I} \pm 0.232$ & $1.426 \pm 0.218^{\# \#}$ & $1.478 \pm 0.217^{\# \#}$ \\
\hline \multirow[t]{2}{*}{ AST (U/L) } & $10-40$ & Placebo & $20.6 \pm 3.9$ & $20.6 \pm 5.0$ & $20.4 \pm 4.8$ \\
\hline & & Rosehip & $20.4 \pm 4.0$ & $21.3 \pm 5.3$ & $21.2 \pm 4.6$ \\
\hline \multirow[t]{2}{*}{$\mathrm{ALT}(\mathrm{U} / \mathrm{L})$} & $5-45$ & Placebo & $21.1 \pm 10.0$ & $21.1 \pm 11.0$ & $21.3 \pm 13.5$ \\
\hline & & Rosehip & $22.8 \pm 8.2$ & $22.2 \pm 9.2$ & $23.6 \pm 9.9$ \\
\hline \multirow[t]{2}{*}{$\gamma$-GTP $(\mathrm{U} / \mathrm{L})$} & M: 79 & Placebo & $39.4 \pm 21.9$ & $39.7 \pm 23.9$ & $39.1 \pm 24.0$ \\
\hline & F: 48 & Rosehip & $28.9 \pm 27.7$ & $25.6 \pm 17.6$ & $24.4 \pm 16.0$ \\
\hline \multirow[t]{2}{*}{ FBS (mg/dL) } & $70-109$ & Placebo & $88.7 \pm 10.7$ & $87.3 \pm 9.5$ & $88.9 \pm 7.9$ \\
\hline & & Rosehip & $83.9 \pm 7.7$ & $87.4 \pm 8.2^{\# \#}$ & $86.5 \pm 8.5$ \\
\hline \multirow[t]{2}{*}{ Total-Cho (mg/dL) } & $150-219$ & Placebo & $205.1 \pm 25.7$ & $205.2 \pm 24.7$ & $207.8 \pm 26.7$ \\
\hline & & Rosehip & $210.1 \pm 25.7$ & $209.6 \pm 25.7$ & $213.1 \pm 30.9$ \\
\hline \multirow[t]{2}{*}{ HDL-Cho (mg/dL) } & M: $40-80$ & Placebo & $60.3 \pm 11.6$ & $57.3 \pm 11.0$ & $62.4 \pm 12.2$ \\
\hline & F: $40-90$ & Rosehip & $55.8 \pm 9.2$ & $56.8 \pm 9.8$ & $58.6 \pm 10.2^{\#}$ \\
\hline \multirow[t]{2}{*}{ LDL-Cho (mg/dL) } & $70-139$ & Placebo & $126.8 \pm 23.6$ & $127.1 \pm 22.3$ & $128.4 \pm 26.1$ \\
\hline & & Rosehip & $|37.4 \pm 2| .8$ & $132.8 \pm 2 \mid .7$ & $136.4 \pm 27.2$ \\
\hline \multirow[t]{2}{*}{ TG (mg/dL) } & $50-149$ & Placebo & $100.9 \pm 36.8$ & $106.3 \pm 31.9$ & $101.1 \pm 32.1$ \\
\hline & & Rosehip & $94.9 \pm 39.2$ & $101.7 \pm 38.8$ & $98.4 \pm 38.1$ \\
\hline \multirow[t]{2}{*}{ Uric acid (mg/dL) } & M: 3.6-7.0 & Placebo & $5.26 \pm 1.11$ & $5.01 \pm 1.02$ & $5.18 \pm 0.92$ \\
\hline & F: $2.7-7.0$ & Rosehip & $5.21 \pm 1.12$ & $5.05 \pm 0.99$ & $5.09 \pm 1.20$ \\
\hline \multirow[t]{2}{*}{ Urea nitrogen (mg/dL) } & $8-20$ & Placebo & $13.44 \pm 2.53$ & $12.88 \pm 2.40$ & $14.26 \pm 3.77$ \\
\hline & & Rosehip & $14.59 \pm 2.77$ & $14.40 \pm 3.64$ & $|4.3| \pm 3.76$ \\
\hline \multirow[t]{2}{*}{ Creatinine (mg/dL) } & M: 0.65-1.09 & Placebo & $0.693 \pm 0.120$ & $0.668 \pm 0.133$ & $0.674 \pm 0.102$ \\
\hline & F: $0.46-0.82$ & Rosehip & $0.649 \pm 0.158$ & $0.649 \pm 0.139$ & $0.649 \pm 0.155$ \\
\hline \multirow[t]{2}{*}{$\mathrm{Na}(\mathrm{mEq} / \mathrm{L})$} & $135-145$ & Placebo & $140.0 \pm 1.0$ & $139.8 \pm 1.0$ & $140.1 \pm 1.6$ \\
\hline & & Rosehip & $|40.7 \pm 1|$. & $140.7 \pm 1.0^{*}$ & $140.8 \pm 1.2$ \\
\hline \multirow[t]{2}{*}{$\mathrm{K}(\mathrm{mEq} / \mathrm{L})$} & $3.5-5.0$ & Placebo & $4.23 \pm 0.22$ & $4.13 \pm 0.32$ & $4.16 \pm 0.35$ \\
\hline & & Rosehip & $4.12 \pm 0.36$ & $4.16 \pm 0.29$ & $4.09 \pm 0.21$ \\
\hline \multirow[t]{2}{*}{$\mathrm{Cl}(\mathrm{mEq} / \mathrm{L})$} & $98-108$ & Placebo & $102.6 \pm 1.6$ & $101.7 \pm 1.7^{\#}$ & $102.5 \pm 2.0$ \\
\hline & & Rosehip & $103.4 \pm 1.9$ & $102.6 \pm 2.4$ & $103.1 \pm 1.7$ \\
\hline \multirow[t]{2}{*}{$\mathrm{Ca}(\mathrm{mg} / \mathrm{dL})$} & $8.2-10.0$ & Placebo & $9.08 \pm 0.38$ & $8.79 \pm 0.45^{\#}$ & $8.84 \pm 0.33^{\#}$ \\
\hline & & Rosehip & $9.09 \pm 0.36$ & $8.89 \pm 0.34^{\#}$ & $8.88 \pm 0.27^{\#}$ \\
\hline
\end{tabular}

Notes: Values represent the mean \pm SD. There was significant difference between the groups according to the Student's $t$-test $(* P<0.05)$. There were significant differences from W0 for each group according to the paired $t$-test $\left(\# P<0.05 ;{ }^{\# P}<0.01\right)$.

Abbreviations: A/G, albumin/globulin; ALT, alanine aminotransferase; AST, aspartate aminotransferase; Cho, cholesterol; F, female; FBS, fasting blood sugar; $\gamma$-GTP, $\gamma$-glutamyl transpeptidase; HDL, high-density lipoprotein; LDL, low-density lipoprotein; M, male; SD, standard deviation; TG, triglyceride; TP, total protein; W0, start of the intake; W8, 8th week; WI2, 12th week.

or tiliroside depend on the inhibition of lipid accumulation in adipose tissue and the stimulation of fatty acid oxidation. The rosehip tablet used in this study contained $0.1 \mathrm{mg}$ of tiliroside in one tablet. Thus, we expect that tiliroside contributed to the reduction of visceral fat by the rosehip extract, and its effective dose seems very low.

The autonomic nervous system (ANS) participates in the regulation of energy metabolism, and it plays an important role in body weight maintenance. ${ }^{38,39}$ ANS activity can be quantified based on the power spectral analysis of the heart rate variability. ${ }^{40,41}$ A preliminary study showed that the rosehip extract stimulates ANS activity and tends to increase the fat utilization at rest and during exercise based on power spectral analysis of the heart rate variability and an analysis of expired gas in 25 healthy male and female adults. In addition, the visceral fat is more reactive than the subcutaneous fat to lipolysis by catecholamine. ${ }^{42,43}$ In the present study, the abdominal visceral fat area was reduced earlier than the subcutaneous fat area. Hence, it is possible that the fat combustion effect induced by enhanced ANS activity is involved in the body fat-lowering effect of the rosehip extract. 
Table 7 Changes in hematological parameters after the daily intake of placebo or rosehip

\begin{tabular}{|c|c|c|c|c|c|}
\hline & Standard range & Group & Wo & W8 & WI2 \\
\hline \multirow[t]{2}{*}{ WBC $(/ \mu \mathrm{L})$} & $3,500-9,700$ & Placebo & $5,488 \pm 1,178$ & $5,939 \pm 1,255$ & $6,035 \pm 1,593$ \\
\hline & & Rosehip & $5,83 I \pm I, 940$ & $5,443 \pm 1,664$ & $5,4|I \pm I, 4| 6$ \\
\hline \multirow[t]{2}{*}{$\operatorname{RBC}\left(\times 10^{4} / \mu \mathrm{L}\right)$} & M: 438-577 & Placebo & $486.4 \pm 28.8$ & $488.1 \pm 27.3$ & $484.9 \pm 27.2$ \\
\hline & F: $376-516$ & Rosehip & $476.2 \pm 32.6$ & $476.4 \pm 31.0$ & $478.4 \pm 32.0$ \\
\hline \multirow[t]{2}{*}{$\mathrm{Hb}(\mathrm{g} / \mathrm{dL})$} & M: |3.6-|8.3 & Placebo & $14.76 \pm 1.13$ & $14.79 \pm 1.25$ & $|4.66 \pm 1.1|$ \\
\hline & F: $11.2-15.2$ & Rosehip & $14.45 \pm 1.14$ & $14.47 \pm 1.12$ & $14.38 \pm 1.15$ \\
\hline \multirow[t]{2}{*}{$\mathrm{Ht}(\%)$} & M: 40.4-5I.9 & Placebo & $44.88 \pm 3.11$ & $45.19 \pm 3.10$ & $44.31 \pm 2.74^{\#}$ \\
\hline & F: $343-452$ & Rosehip & $43.87 \pm 2.73$ & $44.02 \pm 2.72$ & $43.79 \pm 2.90$ \\
\hline \multirow[t]{2}{*}{$\operatorname{Plt}\left(\times 10^{4} / \mu \mathrm{L}\right)$} & $14.0-37.9$ & Placebo & $23.90 \pm 5.28$ & $25.18 \pm 6.76$ & $24.45 \pm 5.67$ \\
\hline & & Rosehip & $23.23 \pm 5.34$ & $25.33 \pm 6.19^{\#}$ & $23.53 \pm 4.87$ \\
\hline
\end{tabular}

Notes: Values represent the mean \pm SD. There were significant differences from W0 for each group according to the paired $t$-test $\left({ }^{\#}<<0.05\right.$; $\left.{ }^{\prime \prime} P<0.0 \mathrm{I}\right)$.

Abbreviations: F, female; Hb, hemoglobin; Ht, hematocrit; M, male; Plt, platelets; RBC, red blood cells; SD, standard deviation; WBC, white blood cells; W0, start of the intake; W8, 8th week; WI2, I2th week.

It is well known that the body weight and body fat mass are affected by the daily diet and exercise regimens. Thus, we monitored the energy intake and consumption of the subjects, but there were no major changes in the lifestyles of the subjects during the study period. Therefore, the changes detected in the present study were attributable to the rosehip extract, rather than lifestyle changes.

The safety of rosehip extract has already been demonstrated by a single-dose toxicity test, a 30-day repeated-dose toxicity test, and an Ames test (unpublished data). In this study, the results of the safety outcomes, subjective symptoms, and medical assessments demonstrated that no serious adverse events were caused by the test food during the study period. Furthermore, rosehip extract does not interact with nifedipine, a cytochrome P450 3A substrate, according to a pharmacokinetics study in rats (unpublished data). However, a previous study reported that rosehip fruit juice delayed the peak time required to attain the maximum blood concentration $\left(T_{\max }\right)$ and there was a $16 \%$ decrease in the area under the blood concentration-time curve with paracetamol. ${ }^{44}$ Thus, the rosehip extract is generally recognized as safe, but care should be taken when patients who are receiving medication also use rosehip.

In conclusion, the results of the present study demonstrate that rosehip extract may be useful as a supplement to safely reduce abdominal visceral fat in preobese subjects. Therefore,

Table 8 Changes in urinalysis parameters after the daily intake of placebo or rosehip

\begin{tabular}{|c|c|c|c|c|c|c|c|c|c|c|c|c|c|c|c|c|c|}
\hline & \multirow{2}{*}{$\begin{array}{l}\text { Standard } \\
\text { range }\end{array}$} & \multirow[t]{2}{*}{ Group } & \multicolumn{5}{|c|}{ Wo } & \multicolumn{5}{|c|}{ W8 } & \multicolumn{5}{|c|}{ WI2 } \\
\hline & & & - & \pm & + & & & - & \pm & + & & & - & \pm & + & & \\
\hline \multirow[t]{2}{*}{ Urine protein } & $(-)-( \pm)$ & Placebo & 15 & 0 & I & & & 14 & I & 1 & & & 14 & I & I & & \\
\hline & & Rosehip & 15 & 0 & 1 & & & 16 & 0 & 0 & & & 16 & 0 & 0 & & \\
\hline \multirow[t]{2}{*}{ Urine glucose } & $(-)-( \pm)$ & Placebo & 16 & 0 & 0 & & & 16 & 0 & 0 & & & 16 & 0 & 0 & & \\
\hline & & Rosehip & 16 & 0 & 0 & & & 16 & 0 & 0 & & & 16 & 0 & 0 & & \\
\hline \multirow[t]{2}{*}{ Urobilinogen } & $( \pm)$ & Placebo & 0 & 15 & 1 & & & 0 & 16 & 0 & & & 0 & 16 & 0 & & \\
\hline & & Rosehip & 0 & 16 & 0 & & & 0 & 16 & 0 & & & 0 & 16 & 0 & & \\
\hline \multirow[t]{2}{*}{ Bilirubin } & $(-)$ & Placebo & 16 & 0 & 0 & & & 16 & 0 & 0 & & & 16 & 0 & 0 & & \\
\hline & & Rosehip & 16 & 0 & 0 & & & 16 & 0 & 0 & & & 16 & 0 & 0 & & \\
\hline \multirow[t]{3}{*}{ Ketone body } & $(-)$ & Placebo & 16 & 0 & 0 & & & 16 & 0 & 0 & & & 16 & 0 & 0 & & \\
\hline & & Rosehip & 16 & 0 & 0 & & & 16 & 0 & 0 & & & 16 & 0 & 0 & & \\
\hline & & & - & \pm & + & $2+$ & $3+$ & - & \pm & + & $2+$ & $3+$ & - & \pm & + & $2+$ & $3+$ \\
\hline \multirow[t]{2}{*}{ Occult blood } & $(-)$ & Placebo & 14 & 1 & 0 & 0 & I & 14 & 1 & 0 & 0 & I & 14 & I & 0 & 0 & 1 \\
\hline & & Rosehip & 15 & 0 & 0 & 0 & 1 & 15 & $\mathrm{I}$ & 0 & 0 & 0 & 13 & $\mathrm{I}$ & $\mathrm{I}$ & $\mathrm{I}$ & 0 \\
\hline \multirow[t]{2}{*}{ Specific gravity } & $1.008-1.034$ & Placebo & \multicolumn{5}{|c|}{$1.0161 \pm 0.0078$} & \multicolumn{5}{|c|}{$1.0159 \pm 0.0086$} & \multicolumn{5}{|c|}{$1.0149 \pm 0.0088$} \\
\hline & & Rosehip & \multicolumn{5}{|c|}{$1.0159 \pm 0.0063$} & \multicolumn{5}{|c|}{$1.0171 \pm 0.0076$} & \multicolumn{5}{|c|}{$1.0171 \pm 0.0062$} \\
\hline \multirow[t]{2}{*}{$\mathrm{pH}$} & $4.8-7.5$ & Placebo & \multicolumn{5}{|c|}{$6.13 \pm 0.89$} & \multicolumn{5}{|c|}{$6.34 \pm 0.94$} & \multicolumn{5}{|c|}{$5.91 \pm 0.71$} \\
\hline & & Rosehip & \multicolumn{5}{|c|}{$6.13 \pm 0.72$} & \multicolumn{5}{|c|}{$6.4 I \pm 0.93$} & \multicolumn{5}{|c|}{$6.28 \pm 0.88$} \\
\hline
\end{tabular}

Notes: Urine protein, urine glucose, urobilinogen, bilirubin, ketone body, and occult blood: Values indicate the numbers of subjects. The symbols indicate the degree of each item: -, negative; \pm , false-positive; +, positive (mild); $2+$, positive (moderate); $3+$, positive (serious). Specific gravity, pH: values represent the mean \pm SD. There were no significant differences between the groups.

Abbreviations: SD, standard deviation; W0, start of the intake; W8, 8th week; WI2, I2th week. 
it is anticipated that rosehip extract will reduce the risk of cardiovascular disease.

\section{Disclosure}

A Nagatomo, N Nishida and Y Matsuura are employees of Morishita Jintan Co, Ltd, and were not involved in the data analysis. A Noro, Y Kozai, and H Sato are employees of New Drug Research Center, Inc. I Fukuhara is a principal investigator of this clinical study.

\section{References}

1. Spiegelman BM, Flier JS. Obesity and the regulation of energy balance. Cell. 2001;104:531-543.

2. Crowley VE. Overview of human obesity and central mechanisms regulating energy homeostasis. Ann Clin Biochem. 2008;45:245-255.

3. Ninomiya K, Matsuda H, Kubo M, Morikawa T, Nishida N, Yohikawa M. Potent anti-obese principle from Rosa canina: structural requirements and mode of action of trans-tiliroside. Bioorg Med Chem Lett. 2007; 17:3059-3064

4. Cohen M. Rosehip - an evidence based herbal medicine for inflammation and arthritis. Aust Fam Physician. 2012;41:495-498.

5. Rein E, Kharazmi A, Winther K. A herbal remedy, Hyben Vital (stand. powder of a subspecies of Rosa canina fruits), reduces pain and improves general wellbeing in patients with osteoarthritis - a doubleblind, placebo-controlled, randomised trial. Phytomedicine. 2004;11: 383-391.

6. Willich SN, Rossnagel K, Roll S, et al. Rose hip herbal remedy in patients with rheumatoid arthritis - a randomised controlled trial. Phytomedicine. 2010;17:87-93.

7. Chrubasik C, Roufogalis BD, Müller-Ladner U, Chrubasik S. A systematic review on the Rosa canina effect and efficacy profiles. Phytother Res. 2008;22:725-733.

8. Gao X, Björk L, Trajkovski V, Uggla M. Evaluation of antioxidant activities of rosehip ethanol extracts in different test systems. $J$ Sci Food Agric. 2000;80:2021-2027.

9. Lattanzio F, Greco E, Carretta D, Cervellati R, Govoni P, Speroni E. In vivo anti-inflammatory effect of Rosa canina L. extract. J Ethnopharmacol. 2011;137:880-885.

10. Jäger AK, Petersen KN, Thomasen G, Christensen SB. Isolation of linoleic and $\alpha$-linolenic acids as COX-1 and -2 inhibitors in rose hip. Phytother Res. 2008;22:982-984.

11. Olsson ME, Gustavsson KE, Andersson S, Nilsson A, Duan RD Inhibition of cancer cell proliferation in vitro by fruit and berry extracts and correlations with antioxidant levels. J Agric Food Chem. 2004;52:7264-7271.

12. Tayefi-Nasrabadi H, Sadigh-Eteghad S, Aghdam Z. The effects of the hydroalcohol extract of Rosa canina L. fruit on experimentally nephrolithiasic Wistar rats. Phytother Res. 2012;26:78-85.

13. Fujii T, Saito M. Inhibitory effect of quercetin isolated from rose hip (Rosa canina L.) against melanogenesis by mouse melanoma cells. Biosci Biotechnol Biochem. 2009;73:1989-1993.

14. Mandade RJ, Choudhury A, Harsulkar A, Wakade R. Role of the Rosa canina $\mathrm{L}$. leaf extract as an antidiarrheal drug in rodents. Indian J Pharmacol. 2011;43:316-319.

15. Winther K, Apel K, Thamsborg G. A powder made from seeds and shells of a rose-hip subspecies (Rosa canina) reduces symptoms of knee and hip osteoarthritis: a randomized, double-blind, placebo-controlled clinical trial. Scand J Rheumatol. 2005;34:302-308.

16. Roman I, Stănilă A, Stănilă S. Bioactive compounds and antioxidant activity of Rosa canina L. biotypes from spontaneous flora of Transylvania. Chem Cent J. 2013;7:73-82.

17. Jung KY, Oh SR, Park SH, et al. Anti-complement activity of tiliroside from the flower buds of Magnolia fargesii. Biol Pharm Bull. 1998;21: 1077-1078.
18. Matsuda H, Ninomiya K, Shimoda H, Yoshikawa M. Hepatoprotective principles from the flowers of Tilia argentea (Linden): structure requirements of tiliroside and mechanisms of action. Bioorg Med Chem. 2002; 10:707-712.

19. Sala A, Recio MC, Schinella GR, et al. Assessment of the antiinflammatory activity and free radical scavenger activity of tiliroside. Eur J Pharmacol. 2003;461:53-61.

20. Tomczyk M, Tumanov A, Zaniewska A, Surazynski A. The potential mechanism of tiliroside-dependent inhibition of t-butylhydroperoxideinduced oxidative stress in endometrial carcinoma cells. Planta Med. 2010;76:963-968.

21. Kumarasamy Y, Cox PJ, Jaspars M, Rashid MA, Sarker SD. Bioactive flavonoid glycosides from the seeds of Rosa canina. Pharm Biol. 2003;41:237-242.

22. Nagatomo A, Nishida N, Matsuura Y, Shibata N. Rosehip extract inhibits lipid accumulation in white adipose tissue by suppressing the expression of peroxisome proliferator-activated receptor gamma. Prev Nutr Food Sci. 2013;18:85-91.

23. Andersson U, Berger K, Högberg A, Landin-Olsson M, Holm C. Effects of rose hip intake on risk markers of type 2 diabetes and cardiovascular disease: a randomized, double-blind, cross-over investigation in obese persons. Eur J Clin Nutr. 2012;66:585-590.

24. WHO. Obesity: preventing and managing the global epidemic. Report of a WHO consultation. World Health Organ Tech Rep Ser; 2000:894:i-xii, $1-253$.

25. Takahashi H, Mori M. Characteristics and significance of criteria for obesity disease in Japan 2011. Nihon Rinsho. 2013;71:257-261. Japanese.

26. Maki KC, Reeves MS, Farmer M, et al. Green tea catechin consumption enhances exercise-induced abdominal fat loss in overweight and obese adults. $J$ Nutr. 2009;139:264-270.

27. Ministry of Health, Labour and Welfare. Exercise and Physical Activity References for Health Promotion 2006 (EPAR2006): Physical Activity, Exercise, and Physical Fitness. Tokyo, Japan: Ministry of Health, Labour and Welfare; 2006. Japanese.

28. Alberti KG, Zimmet PZ. Definition, diagnosis and classification of diabetes mellitus and its complications. Part 1: diagnosis and classification of diabetes mellitus provisional report of a WHO consultation. Diabet Med. 1998;15:539-553.

29. Matsuzawa Y. The metabolic syndrome and adipocytokines. FEBS Lett. 2006;580:2917-2921

30. Lakka HM, Laaksonen DE, Lakka TA, et al. The metabolic syndrome and total and cardiovascular disease mortality in middle-aged men. JAMA. 2002;288:2709-2716.

31. Isomaa B, Almgren P, Tuomi $\mathrm{T}$, et al. Cardiovascular morbidity and mortality associated with the metabolic syndrome. Diabetes Care. 2001;24:683-689.

32. Hiuge-Shimizu A, Kishida K, Funahashi T, et al. Reduction of visceral fat correlates with the decrease in the number of obesity-related cardiovascular risk factors in Japanese with Abdominal Obesity (VACATIONJ Study). J Atheroscler Thromb. 2012;19:1006-1018.

33. Hiuge-Shimizu A, Kishida K, Funahashi T, et al. Coexistence of visceral fat and multiple risk factor accumulations is strongly associated with coronary artery disease in Japanese (the VACATION-J Study). J Atheroscler Thromb. 2012;19:657-663.

34. Czernichow S, Kengne AP, Stamatakis E, Hamer M, Batty GD. Body mass index, waist circumference and waist-hip ratio: which is the better discriminator of cardiovascular disease mortality risk? Evidence from an individual-participant meta-analysis of 82864 participants from nine cohort studies. Obes Rev. 2011;12:680-687.

35. Matsushita Y, Nakagawa T, Yamamoto S, et al. Associations of visceral and subcutaneous fat areas with the prevalence of metabolic risk factor clustering in 6,292 Japanese individuals: the Hitachi Health Study. Diabetes Care. 2010;33:2117-2119.

36. Andersson U, Henriksson E, Ström K, Alenfall J, Göransson O, Holm C. Rose hip exerts antidiabetic effects via a mechanism involving downregulation of the hepatic lipogenic program. Am J Physiol Endocrinol Metab. 2011;300(1):E111-E121. 
37. Goto T, Teraminami A, Lee JY, et al. Tiliroside, a glycosidic flavonoid, ameliorates obesity-induced metabolic disorders via activation of adiponectin signaling followed by enhancement of fatty acid oxidation in liver and skeletal muscle in obese-diabetic mice. J Nutr Biochem. 2012;23:768-776.

38. Lenard NR, Berthoud HR. Central and peripheral regulation of food intake and physical activity: pathways and genes. Obesity (Silver Spring). 2008;16:S11-S22.

39. Kalsbeek A, Bruinstroop E, Yi CX, Klieverik LP, La Fleur SE, Fliers E. Hypothalamic control of energy metabolism via autonomic nervous system. Ann N Y Acad Sci. 2010;1212:114-129.

40. Akselrod S, Gordon D, Ubel FA, Shannon DC, Berger AC, Cohen RJ. Power spectrum analysis of heart rate fluctuation: a quantitative probe of beat-by-beat cardiovascular control. Science. 1981;213:220-222.
41. Moritani T, Hayashi T, Shinohara M, Mimasa F, Shibata M. Comparison of sympatho-vagal function among diabetic patients, normal controls and endurance athletes by heart rate spectral analysis. J Sports Med Sci. 1993;7:31-39.

42. Hellmér J, Marcus C, Sonnenfeld T, Arner P. Mechanisms for differences in lipolysis between human subcutaneous and omental fat cells. J Clin Endocrinol Metab. 1992;75:15-20.

43. Morimoto C, Tsujita T, Okuda H. Norepinephrine-induced lipolysis in rat fat cells from visceral and subcutaneous sites: role of hormonesensitive lipase and lipid droplets. J Lipid Res. 1997;38:132-138.

44. Åkerman U, Edvinsson L. Influence of fruit drinks with or without lactobacillus Lp299v on the gastrointestinal uptake of paracetamol in man. BMC Res Notes. 2009;2:45.

\section{Publish your work in this journal}

Diabetes, Metabolic Syndrome and Obesity: Targets and Therapy is an international, peer-reviewed open-access journal committed to the rapid publication of the latest laboratory and clinical findings in the fields of diabetes, metabolic syndrome and obesity research. Original research, review, case reports, hypothesis formation, expert opinion and commentaries are all considered for publication. The manuscript management system is completely online and includes a very quick and fair peer-review system, which is all easy to use. Visit http://www.dovepress.com/testimonials.php to read real quotes from published authors.

Submit your manuscript here: http://www.dovepress.com/diabetes-metabolic-syndrome-and-obesity-targets-and-therapy-journal 